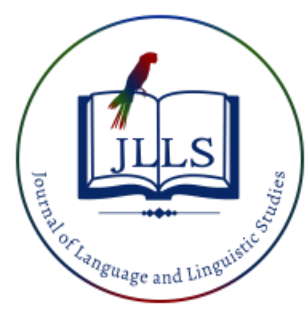

Available online at www.jlls.org

JOURNAL OF LANGUAGE

AND LINGUISTIC STUDIES

ISSN: 1305-578X

Journal of Language and Linguistic Studies, 17(1), 34-55; 2021

\title{
The learnability of word knowledge aspects in Thai EFL high school learners
}

\author{
Worakrit Nontasee $^{\text {a } 1 \text { iD }, ~ A p i s a k ~ S u k y i n g ~}{ }^{\text {b }}$ iD \\ ${ }^{a, b}$ Mahasarakham University, Maha Sarakham, Thailand
}

\begin{abstract}
APA Citation:
Nontasee, W., \& Sukying, A. (2021). The learnability of word knowledge aspects in Thai EFL high school learners. Journal of Language and Linguistic Studies, 17(1), 34-55. Doi: 10.52462/jlls.3

Submission Date: 02/01/2021

Acceptance Date: 12/03/2021
\end{abstract}

\begin{abstract}
This study investigated the learnability of multiple word knowledge aspects and the relationship between the word knowledge aspects. A total of 261 Thai high school students were measured on receptive and productive word knowledge aspects: word parts, the form-meaning link, and collocations. The current findings indicated that word parts are acquired first, followed by the form-meaning link and collocations, which suggest the receptive and productive continuum of learning word knowledge aspects. The present results also indicated an interdepended association between word knowledge aspects. Overall, the findings suggest receptive and productive knowledge of word knowledge aspects is an essential underpinning for vocabulary knowledge growth. Recommendations for future studies are also discussed.
\end{abstract}

Keywords: Word learnability; word knowledge aspects; receptive word knowledge; productive word knowledge; Thai EFL high school learners

\section{Introduction}

Vocabulary knowledge is multidimensional and involves acquiring different word knowledge aspects (Richards, 1976; Nation, 2013; Schmitt, 2014; Schmitt \& Meara, 1997). Research on vocabulary learning showed that word knowledge aspects are continually acquired at different rates (González-Fernández \& Schmitt, 2019; Henriksen, 1999; Laufer, 1998; Laufer \& Goldstein, 2004; Nation, 2013; Schmitt, 2010). The acquisition of one aspect of a word is also associated with other vocabulary knowledge aspects (Nation, 2013; Nontasee \& Sukying, 2020; Schmitt, 2010; Schmitt \& Zimmerman, 2002; Sukying, 2018a, 2020). However, the word learnability (the ease or difficulty of learning a word) differs, depending on the nature of distinct word knowledge aspects. As such, vocabulary learners may face several challenges in learning these multiple word knowledge aspects at different levels (Brown, 2011; González-Fernández \& Schmitt, 2019; Laufer, 1992, 1998; Laufer \& Goldstein, 2004; Milton \& Fitzpatrick, 2014; Nontasee \& Sukying, 2020; Schmitt, 2014; Schmitt \& Meara, 1997; Sukying, 2018b, 2020; Vincy, 2020). However, most studies have investigated only one aspect of word knowledge, particularly the form-meaning relationship (Akbulut, 2017; Chen \&

\footnotetext{
${ }^{1}$ Corresponding author.

E-mail address: n.worakrit@gmail.com
} 
Truscott, 2010; Fitzpatrick \& Izura, 2011; Kieffer \& Lesaux, 2012; Laufer \& Goldstein, 2004; Li \& Kirby, 2015; Meara, 1983; Melka, 1997; Milton \& Fitzpatrick, 2014; Milton \& Hopkins, 2006; Sukying, 2020; Verspoor \& Lowie, 2003). Accordingly, the acquisition of these multiple word knowledge aspects is still under-researched. Moreover, such studies have not investigated the relationship between these interrelated word aspects. This study sought to address this gap by measuring English as a foreign language (EFL) learners' learnability of three-word knowledge aspects: word parts, the form-meaning link, and collocations, both receptively and productively, and examining the relationship between these aspects of a word to better understand the nature of word knowledge acquisition.

\section{Literature review}

As reflected in vocabulary studies, a flurry of scholarly literature has indicated that vocabulary is scrutinized as one of the significant predictors of overall language ability (Anderson \& Freebody, 1981; Laufer, 1989; Nation, 1990, 2013; Schmitt, 2010; Staehr, 2009). Even so, the phenomena of vocabulary knowledge are indefinable. To date, several vocabulary researchers have attempted to theorize word definition and its conceptualization. For example, some lexical researchers (Anderson \& Freebody, 1981, 1983; Palmberg, 1987; Wesche \& Paribakht, 1996) suggest that vocabulary is viewed as the progressive nuances of knowledge with increasing experience and age. The continua of lexical knowledge grow from the trivial familiarity of the individual word and end up fully understanding the particular word in the production with language accuracy. Other vocabulary specialists (Laufer, 1989; Nation, 2001, 2013; Richards, 1976) conceptualize vocabulary knowledge as a range of interconnected 'sub-knowledges,' including orthographical knowledge, linguistic information, and word meaning knowledge. From this vocabulary perspective, word knowledge is more than a part of knowing word form and meaning. Word knowledge and its attributes have been described in several ways.

Based on Richards' (1976) assumptions of word knowledge, Nation $(2001 ; 2013)$ has proposed the most comprehensive word knowledge concepts, which primarily include form, meaning, and use. The construct of word knowledge is illustrated in Table 1.

Table 1. Aspects of word knowledge (Nation, 2013, p. 49)

\begin{tabular}{|c|c|c|c|}
\hline \multirow{6}{*}{ Form } & & $\mathrm{R}$ & What does the word sound like? \\
\hline & Spoken & $\mathrm{P}$ & How is the word pronounced? \\
\hline & & $\mathrm{R}$ & What does the word look like? \\
\hline & & $\mathrm{P}$ & How is the word written and spelled? \\
\hline & & $\mathrm{R}$ & What parts are recognizable in this word? \\
\hline & Word parts & $\mathrm{P}$ & What word parts are needed to express the meaning? \\
\hline \multirow[b]{4}{*}{ Meaning } & & $\mathrm{R}$ & What meaning does this word form signal? \\
\hline & Form and meaning & $\mathrm{P}$ & What word form can be used to express this meaning? \\
\hline & & $\mathrm{R}$ & What is included in this concept? \\
\hline & Concepts and referents & $\mathrm{P}$ & What items can the concept refer to? \\
\hline
\end{tabular}




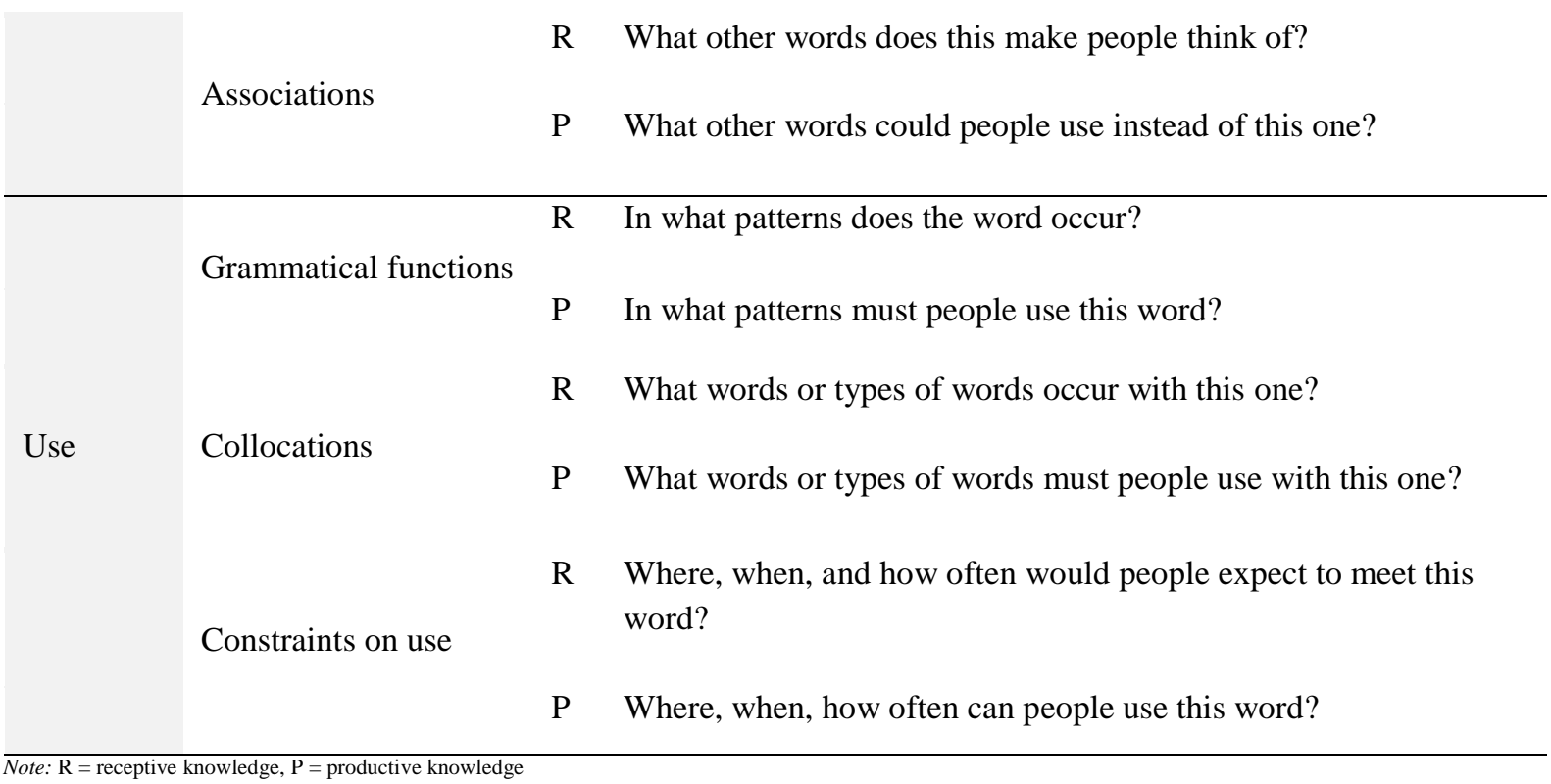

Nation $(1990,2001,2013)$ describes the most comprehensive construct of word knowledge. He lists three main aspects of knowing a word: form, meaning, and use. Knowledge of form encompasses the ability to pinpoint the phonological and morphological elements of a word in both written and spoken modes. The knowledge of meaning entails a learner having insight into form and meaning, concepts and referents, and lexical networks (word associations). Finally, the knowledge of use describes the places in which each word can be used, and the company the word is likely to keep. For example, if a word is an adjective, it will generally be followed by a noun or follows the verb $b e$. If it is a noun, it is then likely to be preceded by an article. Furthermore, some lexical items are likely to occur together while others do not (e.g., be familiar with, be similar to). Accordingly, a learner must understand the unique behavior of the particular word since its use may sometimes entail inappropriate grammatical functions. Nation (2013), therefore, suggests that there are nine different but related aspects of word knowledge, each of which is broken down into receptive $(\mathrm{R})$ and productive $(\mathrm{P})$ levels of mastery (see Table 1). Receptive word knowledge refers to the ability to recognize different forms and meanings of a word, whereas productive word knowledge is the ability to recall and retrieve the forms and meanings of the word and use it appropriately in context (Laufer \& Goldstein, 2004; Sukying, 2017, 2018b).

Previous research on the second language (L2) vocabulary acquisition has shown that knowing a word is crucial for the second language (L2) comprehension and production of vocabulary development (Ellis, 2013; Schmitt, 1998). Word learnability occurs on a developmental continuum of knowing different aspects and is assumed to be acquired at different developmental stages and different rates (e.g., Laufer \& Paribakht, 1998; Nation, 2013; Nontasee \& Sukying, 2020; Schmitt, 2000; Schneider, Healy, \& Bourne, 2002). That is, the ease or difficulty of learning a word depends on the nature of the word's aspects, and understanding the roles of word knowledge can facilitate vocabulary learning (e.g., Akbulut, 2017; Ellis \& Beaton, 1993; Laufer \& Goldstein, 2004; Lin, 2015a, 2015b; Sukying, 2017, 2020; Vincy, 2020). However, the construct of word knowledge remains relatively unexplored in vocabulary learning and acquisition. Paul Meara $(1984,1997)$ first studied vocabulary acquisition and noted the lack of a general theory of vocabulary development, and while many studies have been conducted, a general theory is still lacking.

Recently, González-Fernández and Schmitt (2019) investigated the relationship and order of multiple word knowledge aspects in Spanish learners of English, both receptively and productively. They focused on four aspects: form-meaning link, derivatives, multiple meanings, and collocations. 
The findings revealed a relatively positive relationship between multiple word knowledge aspects, and all aspects, seen as separate constructs, contributed positively to the development of vocabulary. Overall, the findings suggest that the continuum between receptive and productive knowledge of a word is a fundamental conceptualization of vocabulary acquisition and development. Moreover, as an incremental process, the related word knowledge aspects facilitate mastery of a word beneficially.

Although several earlier studies have explored word knowledge acquisition (e.g., Daskalovska, 2016; Henriksen, 1999), this process is still not well understood, and conflicting results have been reported. This is perhaps because these studies have scrutinized only one single aspect of word knowledge, particularly the form and meaning of a word, and have relied on different concepts, contexts, and instruments (e.g., Milton \& Fitzpatrick, 2014; Laufer \& Goldstein, 2004). For example, it has previously been reported that some productive aspects are acquired before some receptive aspects, while others show that receptive aspects are mastered before productive aspects (Nontasee \& Sukying, 2020; Pellicer-Sánchez \& Schmitt, 2010; Pigada \& Schmitt, 2006). Furthermore, there seems to be no consensus on how word knowledge aspects are generally acquired and the relationship between these aspects (Milton \& Fitzpatrick, 2014; Schmitt, 2014). As such, more empirical research focusing on the word knowledge framework (Nation, 2013) in the field of vocabulary acquisition is required.

The vocabulary learning seems to be an excessive obstacle for English language learning, especially for EFL learners. Previous studies indicate that EFL learners had low proficiency in word knowledge, both receptively and productively (Hayashi \& Murphy, 2011; Nontasee \& Sukying, 2020; Sukying, 2017, 2018b). Many studies have attempted to investigate the importance of vocabulary learning and word knowledge (e.g., Liangpanit, 2014; Kittigosin \& Phoocharoensil, 2015; Phoocharoensil, 2013, 2014; Sukying, 2017, 2020; Supa-Siraprapa, 2019). However, only a handful of research studies emphasize the acquisition of word knowledge aspects. For instance, one study investigated receptive and productive affix knowledge in Thai high school learners and found that their affix knowledge was relatively low, both receptively and productively (Sukying, 2018b). Another study also examined receptive and productive vocabulary knowledge and found poor knowledge of English collocations in Thai university learners (Supa-Siraprapa, 2019). Furthermore, a study investigating Thai EFL students' receptive and productive vocabulary size demonstrated that students' receptive vocabulary size was almost double their productive vocabulary size, and the students showed low English proficiency (Kotchana \& Tongpoon-Patanasorn, 2015). Despite years of learning English, the most significant difficulty in English language use faced by Thai learners appears to be a lack of word knowledge (e.g., Chawwang, 2008; Jamtawee, 2000; Kotchana \& Tongpoon-Patanasorn, 2015).

Understanding the nature of word learnability may help guide and improve the explicit teaching of vocabulary and enhance EFL students' vocabulary learning (Webb, 2005, 2009; Sukying, 2020). Specifically, a better understanding of word aspects' interrelatedness would advance word knowledge acquisition and use (Schmitt \& Meara, 1997). Understanding the nature of multiple word knowledge aspects within the word knowledge framework will also provide a clearer picture of word knowledge acquisition in language learners. Therefore, this study will examine L2 word learnability by measuring the three different aspects of a word (word parts, the form-meaning link, and collocations) and their impact on learning a word, both receptively and productively. The study will also investigate the relationship between different aspects of a word by adopting Nation's (2013) framework of word knowledge. Specifically, the current study aims to address the following research questions:

1. What is the learnability of word knowledge aspects in Thai high school learners?

2. What is the relationship between word knowledge aspects in Thai high school learners? 


\section{Method}

\subsection{Participants}

The current study was conducted at a local high school under the government university administration in the northeast of Thailand. The students had a range of English language abilities varying from advanced beginners to upper-intermediate. The rationale for recruiting Thai participants was to investigate L2 word learnability in a Thai EFL context. Thai students have experience learning English for many years, but they have limited English language exposure. Therefore, it is interesting to examine their comprehension and production of English, and specifically, their experienced ease or difficulty in learning English words.

The participants were 261 Thai students in tenth, eleventh, or twelfth-grade high school, who had studied English for more than ten years. All participants were EFL students and ranged from 16 to 18 years of age when the data was collected. Participants were given a battery of tests before the study to measure their ability to learn a word. The participants had not received any training in the types of tasks used in the current study. Overall, the senior high school students were categorized as the intermediate level of English proficiency. These students were all able to use high-frequency vocabulary and continue their English studies at a higher level of academic education. This group's word knowledge was considered consistent with their education level (Hayashi \& Murphy, 2011; Sukying, 2017). All participants were Thai native speakers using their L1 to communicate with their friends or classmates at school, and none had studied English in an English-speaking country. The participants received an average of four hours of English instruction per week, including four 50minute English sessions with EFL teachers and one 50-minute session with native English speakers. Consistent with the Office of the Basic Education Commission (Ministry of Education in Thailand), all participants had been enrolled in EFL classes for a minimum of 10 years as a mandatory subject. While the participants also had access to English language media, including the internet, news articles, movies, radio, and television, they rarely availed themselves of such sources due to their inability to autonomously understand them. Therefore, Thai students' level of exposure to the English language was assumed to be restricted to their classroom instruction.

\subsection{Selecting the prompt words}

The prompt words were carefully chosen based on the recommendations provided by Morgan and Bonham (1944) and Meara (1983). Specifically, it is recommended that the prompt words are neutral in terms of difficulty and are neither the easiest nor the most complicated grammatical class of words. To ensure that the prompt words were sufficiently familiar and appropriate to measure the ability of word knowledge, both receptively and productively, words were selected that are common in daily life and the area of academic study. The prompt words were selected from two-word lists, the Academic Word List (AWL) (Coxhead, 2000) and the New General Service List (NGSL) (Browne, Culligan, \& Phillips, 2013), and the words were piloted by 50 senior high school students who were not involved in the main study. The familiarity of the words for a high school level was verified by comparing these words with the Preliminary for Schools Vocabulary List developed by Cambridge English for the CEFR (B1 level) and with Thailand's Basic Education Curriculum B.E. 2544 (A.D. 2001) developed by the Ministry of Education of Thailand. The collocational words were also verified on websites, including the Longman Dictionary of Contemporary English and the Online Oxford Dictionary. The prompt words were also derived as a word family to meet the concept of L2 word learnability in word knowledge. Finally, the appropriateness of the prompt words for a Thai high school context was 
examined by five experts to ensure that the content of the tests was sufficiently familiar to the senior high school students.

\subsection{Instruments}

Six research instruments were used to measure the three aspects of a word, including word parts, form-meaning link, and word collocations, on both receptive and productive dimensions. Content validity was assessed by five experts in the area of English education, with approximately ten years' experience, including one native speaker, one university teacher, and three high school teachers. Additionally, all six tests were piloted with 120 senior high school students to examine the validity and reliability of tests.

\subsubsection{The Word Segmentation Test (WST)}

The WST was designed and developed based on Hayashi and Murphy (2011) as a receptive measure of word form. More specifically, this test is used to measure receptive knowledge of word parts. The test includes 40 items, with one verb, twenty-three nouns, six adverbs, and ten adjectives. Participants are required to break down word components into smaller morphemes, the smallest meaningful part of a language. The morphemes used in the current study are based on Bauer and Nation's (1993) word family criteria. Regarding scoring, one morpheme was awarded one point, and no points are awarded for no answer or an incorrect answer, such as a wrong root word. The scoring criteria of the word segmentation task are shown in Table 2.

Table 2. The Word Segmentation Test Scores

\begin{tabular}{lc}
\hline Instructions: Break down a word into the smallest parts & Point \\
\hline unhappiness = un+happy+ness & 3 \\
happily = happy+ly & 2 \\
unhappiness = unhappy+ness & 2 \\
happily = happily & 0 \\
happily = happi + ly & 0 \\
\hline
\end{tabular}

\subsubsection{The Affix Elicitation Test (AET)}

The AET was also designed and developed based on Hayashi and Murphy's (2011) study to measure learners' productive knowledge of word parts. The test includes 20 items. Participants are asked to supply a correct form of a word for each blank in the sentence and also to provide a syntactic class for the derived word. No points were awarded for no answer or an incorrect answer. One point was awarded for each correct response, including a correct form in context and a correct type of a derived word. The scoring criteria for this task are shown in Table 3.

Table 3. The Affix Elicitation Test Scores

Instructions: Choose an appropriate part of speech in part B to complete the sentence in part A

\begin{tabular}{l|c|c|c|c|c|c|c}
\hline Part A & Point & \multicolumn{3}{|c|}{ Part B } & Point & Total \\
\hline & & N. & V. & Adj. & Adv. & & \\
\hline He is a manager (manage). & 1 & $X$ & & & & 1 & 2 \\
\hline He is a manager (manage). & 1 & & $X$ & & & 0 & 1 \\
\hline
\end{tabular}




\begin{tabular}{l|l|l|l|l|l|l|l}
\hline He is a manager (manage). & 0 & $X$ & & & & 1 & 1 \\
\hline He is a manager (manage). & 0 & & & $X$ & & 0 & 0 \\
\hline
\end{tabular}

\subsubsection{The L2 Translation Test (L2TT)}

The L2TT was designed and developed based on previous studies (Nation \& Beglar, 2007; Nation, 1983, 1990). The test is a receptive measure of word meaning and is used to measure receptive knowledge of the form-meaning aspect. It is formatted as a multiple-choice test and the participant is presented with four options and must select the answer with the same definition as the prompt word. The test included 40 items. To avoid providing any suggestions on the association of the word category, all of the words in each set of the vocabulary battery are presented in the same part of speech. No points were awarded for a blank or an incorrect answer. One point was awarded for each correct response. An example of this test is shown below in Table 4:

Table 4. The L2 Translation Test Scores

\begin{tabular}{|c|c|c|}
\hline Instructions: Choose the word with a similar meaning & Answer & Point \\
\hline 1. book & & \\
\hline a) reserve & correct & 1 \\
\hline b) revenge & incorrect & 0 \\
\hline c) remove & incorrect & 0 \\
\hline d) restore & incorrect & 0 \\
\hline
\end{tabular}

\subsubsection{The L1 Translation Test (L1TT)}

The L1TT was developed based on Laufer and Goldstein (2004). This test is a productive measure of word meaning and is primarily used to measure the ability to recall a word in the knowledge of the form-meaning aspect. The test is comprised of 20 lines with one line for each prompt word. The instructions encourage the participants to recall the meaning of each prompt word. Participants are given the Thai words and required to supply the definition of a word in English by following a given letter. A correct word definition is awarded one point, and no points are given for no answer or an incorrect answer. An example of this test is shown in Table 5.

Table 5. The L1 Translation Test Scores

Instructions: Read the meaning of the following words in Thai and complete the English words with the first letter given

\begin{tabular}{|c|c|c|c|}
\hline Word Questions & Answer & Correct Answer & Point \\
\hline 1. นาพิกา & $\mathrm{W} \underline{\text { atch }}$ & Watch & 1 \\
\hline 2. การอ่าน & $\mathrm{R} \underline{e a d}$ & Reading & 0.5 \\
\hline 3. อย่างมีความสุข & $\mathrm{H} \underline{a p p y}$ & Happily & 0.5 \\
\hline
\end{tabular}

\subsubsection{The Collocation Recognition Test (CRT)}

The CRT was designed and developed based on Schmitt, Schmitt, and Clapham (2001) as a receptive measure of word use. This test is used to assess learners' receptive knowledge of word collocations and included 40 collocational items. Participants are asked to match the correct word collocation to the appropriate context by selecting among the given words. No points are given for 
incorrect or blank answers, and one correct match was awarded one point. An example of this test is shown in Table 6.

Table 6. The Collocation Recognition Test Scores

Instructions: Choose the best word choice in the first column to describe the noun in the second

\begin{tabular}{llcc}
\hline Adjective & Noun & Correct Answer & Point \\
\hline big & 1. flip chart & 1. flip & 1 \\
external & 2. large success & 2. big & 0 \\
large & & & \\
flip & & & \\
\hline
\end{tabular}

\subsubsection{The Productive Collocation Recall Test (PCRT)}

The PCRT was developed based on previous studies (Begagić, 2016; Laufer \& Nation, 1995; 1999) as a productive measure of word use. The test was designed as a gap-filling test to measure learners' productive knowledge of word collocations. Only one correct answer is allowed. The target collocations' initial letters were provided to avoid non-target words that may fit the allocated sentence and prevent guessing and ensure that the participants would select only the prompt word. The test included 20 collocational items. The correct answer was awarded one point, and no points were given for incorrect or blank answers. Examples from the collocation recall test are shown in Table 7.

Table 7. The Productive Collocation Recall Test

\begin{tabular}{|c|c|c|}
\hline $\begin{array}{l}\text { Instructions: Complete the sentence below with an appropriate } \\
\text { word }\end{array}$ & Correct Answer & Point \\
\hline 1. The Beatles is a fa_mous_ _ band in Thailand & famous & 1 \\
\hline 2. Do you want to hear the good or ba_ $\underline{d} \_$news first? & bad & 1 \\
\hline
\end{tabular}

\subsection{Data collection procedures}

Six types of tests were used to evaluate receptive and productive word knowledge. To ensure that participants will not transfer knowledge from a receptive test to a productive test or draw a connection between different aspects of word knowledge, productive knowledge tests were given to all participants before the receptive knowledge tests, and the test of word use was the first to be administered. Indeed, the ability to supply the word form as productive knowledge can be transferred to the ability to supply the word meaning as receptive knowledge (Laufer \& Goldstein, 2004); thus, the test of word meaning must be conducted before the measure of word form. The six tests were administered as follows: 1) the collocation recall test, 2) the collocation recognition test, 3) the L1 translation test, 4) the L2 translation test, 5) the affix elicitation task, and 6) the word segmentation task. A summary of the data collection procedure is shown in Table 8.

Table 8. Summary of the Data Collection Procedure

\begin{tabular}{|c|c|c|c|c|c|}
\hline Day & Productive knowledge & Time & Receptive knowledge & Time & \\
\hline 1 & 1) The collocation recall test & \multirow{2}{*}{20 minutes } & 2) The collocation recognition test & \multirow{2}{*}{$\begin{array}{c}40 \\
\text { minutes }\end{array}$} & \multirow{2}{*}{$N=261$} \\
\hline 2 & 3) The L1 translation test & & 4) The L2 translation test & & \\
\hline
\end{tabular}


6) The word segmentation task

\subsection{Data analysis}

The test scores obtained by each research instrument were analyzed with the Statistical Package for the Social Sciences (SPSS) (Larson-Hall, 2016; Larson-Hall \& Herrington, 2010). The probability coefficient (p), which can range from 0 to $=1$, was calculated, and the significance level was set at 0.05 to reject the null hypothesis (Dörnyei, 2007). According to Mackey and Gass (2005), Cronbach's Alpha is a measure of internal consistency and reliability. Based on DeVellis (2003), the Cronbach's Alpha coefficient of a scale should be above 0.70, and internal consistency indicators for a welldeveloped test need to approach 0.80 (Dörnyei, 2007).

Table 9. A Summary of Data Analysis

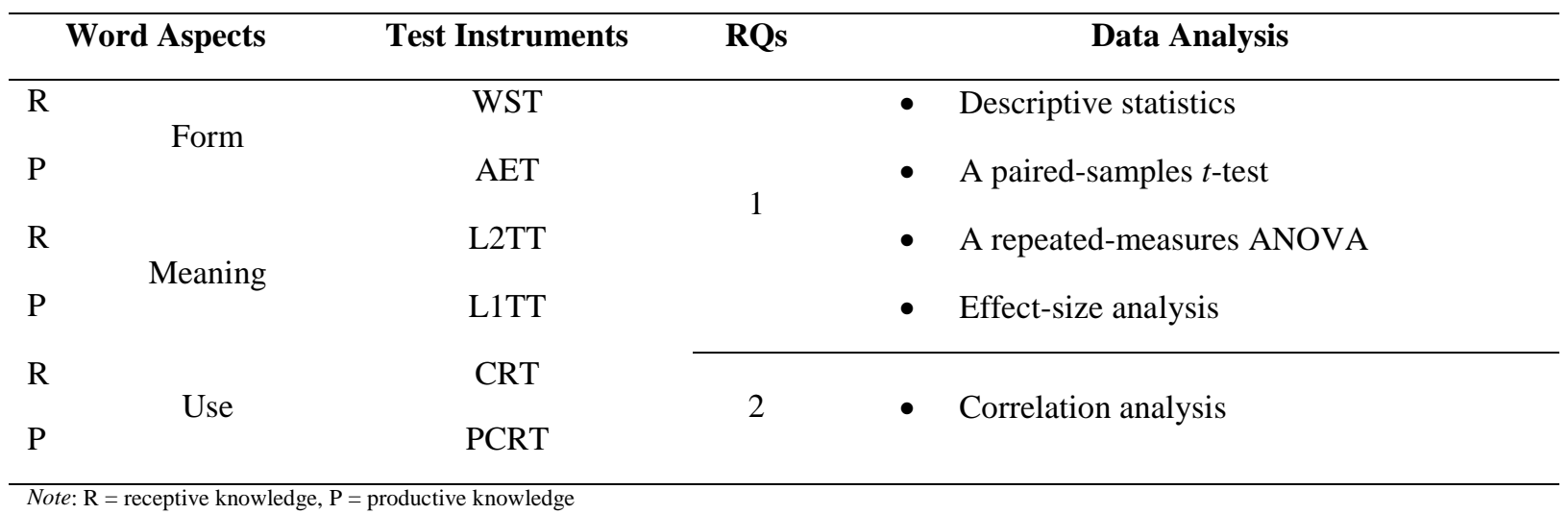

Descriptive statistics, including means and standard deviations, were conducted to describe participants' test performance on word knowledge. Means refer to average scores, and standard deviations indicate how scores are spread around the mean (Mackey \& Gass, 2005). Correlations was calculated to reveal the relationship between different word tests based on Cohen's (1988) guidelines: small, $r=0.10$ to 0.29 ; medium, $r=0.30$ to 0.49 ; large, $r=0.50$ to 1.0 . Additionally, a paired-samples $t$-test and repeated-measures ANOVA were conducted to detect any significant differences in word learnability. Cohen's $d$ was used to calculate the effect size of any differences, with an effect size of 0.30 considered small, 0.50 considered medium, and 0.80 considered large (Cohen, 1992).

\section{Results}

The six tests [the Word Segmentation Test (WST), the Affix Elicitation Test (AET), the L2 Translation Test (L2TT), the L1 Translation Test (L1TT), the Collocation Recognition Test (CRT), and the Collocation Productive Recall Test (CPRT)] were used to measure the participants' word knowledge. The tests scored 0.78 (WST), 0.70 (AET), 0.71 (L2TT), 0.76 (L1TT), 0.73 (CRT), and 0.77 (CPRT) on Cronbach's Alpha for internal consistency, indicating acceptable reliability in measuring word knowledge aspects (DeVellis, 2003; Dörnyei, 2007).

This section answers Research Question 1: What is the learnability of word knowledge aspects in Thai high school learners? The results showed that there was a significant difference between receptive and productive word measures. The participants performed better on receptive word tests, indicated by higher average scores than on productive word tests on all aspects. The performance of each test was relatively low; specifically, only receptive form measure was higher over 50 percent of a total score. The summary for senior high school students' performance on the word tests is presented in Table 10 . 
Table 10. Performance of the Word Knowledge Tests

\begin{tabular}{|c|c|c|c|c|c|c|}
\hline Worc & & Tests & Mean (\%) & SD & $t$-value & Effect-size \\
\hline \multirow{2}{*}{ Form } & $\mathrm{R}$ & WST & 71.49 & 13.07 & \multirow{2}{*}{70.51} & \multirow{2}{*}{$\eta^{2}=4.59$} \\
\hline & $\mathrm{P}$ & $\mathrm{AET}$ & 19.98 & 9.38 & & \\
\hline \multirow{2}{*}{ Meaning } & $\mathrm{R}$ & L2TT & 28.15 & 6.54 & \multirow{2}{*}{38.87} & \multirow{2}{*}{$\eta^{2}=2.85$} \\
\hline & $\mathrm{P}$ & L1TT & 14.84 & 2.80 & & \\
\hline \multirow{2}{*}{ Use } & $\mathrm{R}$ & CRT & 22.57 & 7.76 & \multirow{2}{*}{35.60} & \multirow{2}{*}{$\eta^{2}=2.45$} \\
\hline & $\mathrm{P}$ & PCRT & 8.18 & 3.96 & & \\
\hline
\end{tabular}

The results show that participants performed better on the WST (71.49\%), followed by L2TT (28.15), CRT (22.57\%), AET (19.98\%), L1TT (14.84\%), and PCRT (8.18\%), respectively. A paired samples $t$-test showed that the mean scores for receptive and productive knowledge of a word on the word measures were significantly different and with a large effect size. Specifically, the mean scores on the WST and AET were significantly different $\left(t=70.51, \eta^{2}=4.59\right)$. Similarly, the mean scores on the L2TT and L1TT revealed a significant difference $\left(t=38.87, \eta^{2}=2.85\right)$. Finally, the mean scores on the CRT and PCRT showed a significant difference $\left(t=35.60, \eta^{2}=2.45\right)$.

The analysis also revealed significant differences in test performance between all different word measures, and all comparisons revealed a large effect size.

Table 11. Comparison Performance for All Different Aspects of Word Knowledge on the Different Measures

\begin{tabular}{|c|c|c|c|c|c|c|}
\hline \multicolumn{2}{|c|}{ Word aspects } & Tests & Mean (\%) & SD & $t$-value & Effect-size \\
\hline Form & $\mathrm{R}$ & WST & 71.49 & 13.07 & \multirow{2}{*}{59.96} & \multirow{2}{*}{$\eta^{2}=13.26$} \\
\hline Meaning & $\mathrm{R}$ & L2TT & 28.15 & 6.54 & & \\
\hline Form & $\mathrm{R}$ & WST & 71.49 & 13.07 & \multirow{2}{*}{63.11} & \multirow{2}{*}{$\eta^{2}=18.46$} \\
\hline Use & $\mathrm{R}$ & CRT & 22.57 & 7.76 & & \\
\hline Form & $\mathrm{R}$ & WST & 71.49 & 13.07 & \multirow{2}{*}{77.36} & \multirow{2}{*}{$\eta^{2}=11.04$} \\
\hline Meaning & $\mathrm{P}$ & L1TT & 14.84 & 2.80 & & \\
\hline Form & $\mathrm{R}$ & WST & 71.49 & 13.07 & \multirow{2}{*}{83.41} & \multirow{2}{*}{$\eta^{2}=13.91$} \\
\hline Use & $\mathrm{P}$ & PCRT & 8.18 & 3.96 & & \\
\hline Meaning & $\mathrm{R}$ & L2TT & 28.15 & 6.54 & \multirow{2}{*}{15.92} & \multirow{2}{*}{$\eta^{2}=9.14$} \\
\hline Use & $\mathrm{R}$ & CRT & 22.57 & 7.76 & & \\
\hline Meaning & $\mathrm{R}$ & L2TT & 28.15 & 6.54 & \multirow{2}{*}{17.05} & \multirow{2}{*}{$\eta^{2}=5.75$} \\
\hline Form & $\mathrm{P}$ & AET & 19.98 & 9.38 & & \\
\hline Meaning & $\mathrm{R}$ & L2TT & 28.15 & 6.54 & \multirow{2}{*}{55.01} & \multirow{2}{*}{$\eta^{2}=15.48$} \\
\hline Use & $\mathrm{P}$ & PCRT & 8.18 & 3.96 & & \\
\hline Use & $\mathrm{R}$ & CRT & 22.57 & 7.76 & \multirow{2}{*}{4.75} & \multirow{2}{*}{$\eta^{2}=1.59$} \\
\hline Form & $\mathrm{P}$ & AET & 19.98 & 9.38 & & \\
\hline
\end{tabular}




\begin{tabular}{|c|c|c|c|c|c|c|}
\hline Use & $\mathrm{R}$ & CRT & 22.57 & 7.76 & \multirow{2}{*}{17.71} & \multirow{2}{*}{$\eta^{2}=3.11$} \\
\hline Meaning & $\mathrm{P}$ & L1TT & 14.84 & 2.80 & & \\
\hline Form & $\mathrm{P}$ & AET & 19.98 & 9.38 & \multirow{2}{*}{9.83} & \multirow{2}{*}{$\eta^{2}=1.56$} \\
\hline Meaning & $\mathrm{P}$ & L1TT & 14.84 & 2.80 & & \\
\hline Form & $\mathrm{P}$ & AET & 19.98 & 9.38 & \multirow{2}{*}{21.88} & \multirow{2}{*}{$\eta^{2}=4.35$} \\
\hline Use & $\mathrm{P}$ & PCRT & 8.18 & 3.96 & & \\
\hline Meaning & $\mathrm{P}$ & L1TT & 14.84 & 2.80 & \multirow{2}{*}{26.91} & \multirow{2}{*}{$\eta^{2}=11.48$} \\
\hline Use & $\mathrm{P}$ & PCRT & 8.18 & 3.96 & & \\
\hline
\end{tabular}

Table 11 illustrates that performance on the WST was significantly different to performance on the L2TT $\left(t=59.961, \eta^{2}=13.26\right)$, the CRT $\left(t=63.117, \eta^{2}=18.46\right)$, the L1TT, $\left(t=77.368, \eta^{2}=11.04\right)$, and the PCRT $\left(t=83.410, \eta^{2}=13.91\right)$. Similarly, performance on the L2TT was significantly different to performance on the CRT $\left(t=15.926, \eta^{2}=9.14\right)$, the AET $\left(t=17.054, \eta^{2}=5.75\right)$, and the PCRT $(t=$ $\left.55.013, \eta^{2}=15.48\right)$. Performance on the CRT also significantly differed from performance on the AET $\left(t=4.754, \eta^{2}=1.59\right)$, and the L1TT $\left(t=17.716, \eta^{2}=3.11\right)$. The AET performance also differed from L1TT performance $\left(t=9.834, \eta^{2}=1.56\right)$, PCRT performance $\left(t=21.884, \eta^{2}=4.35\right)$. Finally, the L1TT performance was also significantly different to the PCRT performance $\left(t=26.915, \eta^{2}=11.48\right)$. All comparisons revealed a large effect size.

Table 12. Comparison Performance of a Repeated-Measures ANOVA

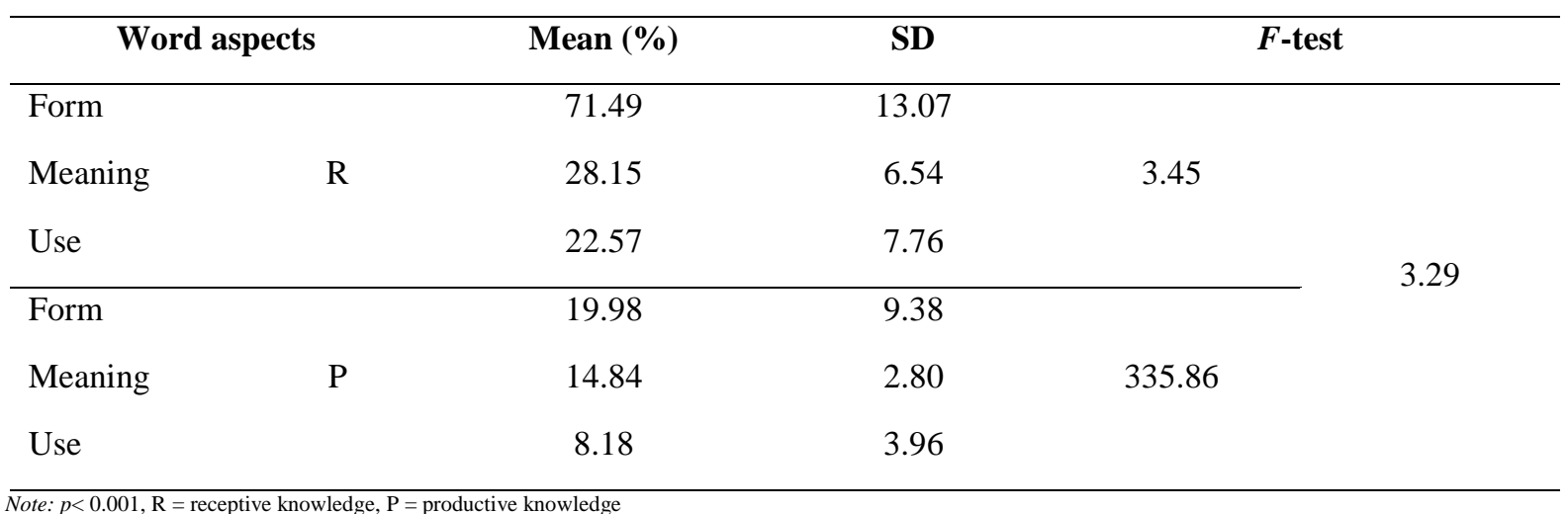

A repeated-measures ANOVA with a Greenhouse-Geisser correction indicated that the mean scores for receptive knowledge on the WST, L2TT, and CRT performance were significantly different $(F=3.45)$, and there was a significant difference between the test performances on the productive word knowledge measures, the AET, L1TT, and PCRT $(F=335.86)$. Finally, the mean scores on the WST, AET, L2TT, L1TT, CRT, and PCRT performance were significantly different $(F=3.29)$.

Consequently, the findings revealed significant differences between all different measures, suggesting varying difficulties for different aspects of a word. This also indicates that productive knowledge of a word is more difficult to acquire than receptive knowledge of a word.

This section answers Research Question 2: What is the relationship between word knowledge aspects in Thai high school learners? A correlation analysis was conducted to examine the relationships between different word tests, including the associations between the aspects of a word: form, meaning, and use, both receptively and productively. 
Table 13. Correlations between Word Knowledge Measures

\begin{tabular}{ccccccc}
\hline Tests & WST & AET & L2TT & L1TT & CRT & PCRT \\
\hline WST & 1 & & & & & \\
AET & 0.48 & 1 & & & & \\
L2TT & 0.45 & 0.57 & 1 & 1 & & \\
L1TT & 0.53 & 0.46 & 0.54 & 0.42 & 1 & 1 \\
CRT & 0.36 & 0.48 & 0.69 & 0.42 & \\
PCRT & 0.35 & 0.37 & 0.46 & 0.34 & 0.54 & \\
\hline Note: $p<0.001, N=261$ & & & & &
\end{tabular}

As shown in Table 13, the correlations analysis results revealed that the tests were highly correlated, revealing medium to high correlations between all six tests. Specifically, there was a high correlation between the WST and the L1TT $(r=0.53)$, the AET and the L2TT $(r=0.57)$, the L2TT and the L1TT $(r=0.54)$, the L2TT and the CRT $(r=0.69)$, and the CRT and the PCRT $(r=0.54)$. The relationships between the WST and the AET $(r=0.48)$, the WST and the L2TT $(r=0.45)$, the WST and the CRT $(r=0.36)$, the WST and the PCRT $(r=0.35)$, the AET and the L1TT $(r=0.46)$, the AET and the CRT $(r=0.48)$, the AET and the PCRT $(r=0.37)$, the L2TT and the PCRT $(r=0.46)$, the L1TT and the CRT ( $r=0.42)$, and the L1TT and the PCRT $(r=0.34)$, were considered medium relationships. At last, there was no small relationship. This finding indicates that significant positive relationships exist between different word tests, especially receptive knowledge of a word and productive knowledge of a word, suggesting that the acquisition of multiple word knowledge aspects is an incremental learning process.

Overall, the results reveal that there are varying degrees of word knowledge. Specifically, the word aspect 'form' received the highest average performance, followed by the meaning of the word and, finally, the use of word knowledge. Furthermore, the analysis also demonstrated a significant difference between the receptive and productive word measures with a large effect size. The results suggest that word knowledge aspects are not acquired simultaneously, and productive knowledge of a word is more difficult to acquire than receptive knowledge of a word. In addition, this also reveals that different aspects of a word are positively correlated. Specifically, there was also a relatively positive relationship between receptive and productive knowledge of a word, suggesting that receptive knowledge can promote productive knowledge when learning a word. Overall, these findings confirm that vocabulary learning is a developmental continuum.

\section{Discussion}

The current study investigated L2 word learnability and the relationship between different word knowledge aspects to better comprehend the ease or difficulty with which a word is learned in Thai EFL learners. Two research questions were formulated for this study. Research Question 1 examined the learnability of word knowledge aspects in Thai high school learners. Research Question 2 examined the relationship between different word knowledge aspects. The participants' knowledge of the form, meaning, and use of a word was assessed by six measures, including word part knowledge, form-meaning knowledge, and collocations, both receptively and productively. The current study results showed that Thai EFL participants had poor word knowledge and showed better receptive knowledge than productive knowledge. The participants performed best in word parts (form), followed by form-meaning link (meaning) and word collocations (use). This phenomenon can be accounted for 
by the incremental development of word knowledge and suggests that a word's learnability is acquired in different stages and at different rates. These findings are consistent with previous studies (e.g., Henriksen, 1999; Laufer \& Goldstein, 2004; Laufer \& Nation, 1999; Laufer \& Paribakht, 1998; Lin, 2015a, 2015b; Read, 2000; Schmitt \& Meara, 1997; Meara \& Buxton, 1987; Nation, 2013; Schmitt, Schmitt, \& Clapham, 2001; Sukying, 2017, 2018a, 2018b, 2020).

In response to Research Question 1 regarding L2 word learnability in Thai EFL learners, the results provide clear evidence that receptive and productive performance differs in Thai EFL learners. Thai high school participants performed better on receptive knowledge measures than productive knowledge measures, with a large effect size. This indicates that the productive measures may inflict a heavier processing demand on Thai EFL participants than the receptive measures. These findings are consistent with earlier results that productive measures are more difficult than receptive measures. Indeed, a productive measure requires that the learner produces a correct answer in a spontaneous context, which generates a greater processing demand than being asked to complete or recognize an answer (Corson, 1995; Hayashi \& Murphy, 2011; Laufer \& Goldstein, 2004; Lin, 2015b; Sukying, 2017). However, some productive aspects can be easier to acquire than some receptive aspects (Pigada \& Schmitt, 2006). For example, the receptive spelling knowledge was found to be easier to acquire than the productive grammatical knowledge. The receptive knowledge of a word may indeed advance the productive knowledge of a word. Correctly producing a word demands the comprehension of a word and, therefore, receptive knowledge is often prioritized in English learning before mastering the production of a word. This suggests that if the students' vocabulary size or word knowledge was insufficient, it could affect their ability to produce a word (Hayashi \& Murphy, 2011; Pellicer-Sánchez \& Schmitt, 2010; Sukying, 2017).

Regarding word knowledge aspects, the current study also showed various levels of difficulty for word knowledge. The results demonstrated that participants performed differently on the tests assessing distinct aspects of a word, with a large effect size. Specifically, Thai high school participants performed best on word parts, followed by the form-meaning link, and collocations, both receptively and productively. This indicates that the form of word knowledge is the easiest to achieve, followed by the meaning and use, respectively. The findings suggest that word knowledge may be acquired in the different stages and at different rates, and word knowledge aspects do not seem to be mastered simultaneously, which is consistent with previous literature on vocabulary learning (GonzálezFernández \& Schmitt, 2019; Nontasee \& Sukying, 2020).

The findings are also consistent with previous literature showing that while comprehensive knowledge of a word requires understanding all aspects of knowledge, both receptively and productively, EFL learners may only acquire some aspects at a time. For instance, spoken and written forms of a word may be acquired before or after attaining the word meaning. The learners seem to learn a single meaning in a context and, with increasing exposure to the word, they will acquire other meanings. By contrast, the word usage, such as register or pragmatic constraints and collocations, may be learned relatively late because these aspects demand a deep understanding and a high level of lexical and grammatical knowledge. Indeed, mastery of a word depends on the exposure of a word, which requires embedding the word in the appropriate contexts (Nation, 2013; Sukying, 2020).

Consistent with previous studies (Henriksen, 1999; Pellicer-Sánchez \& Schmitt, 2010), GonzálezFernández and Schmitt (2019) also noted that the form-meaning link was well-known and typically occurred before other aspects. Specifically, the morphological knowledge (affixation) and the syntactical knowledge of word family members is learned relatively late (Nagy, Diakidoy \& Anderson, 1993; Barcroft, 2002) and require explicit teaching (Barcroft, 2002; Chui, 2006). However, this differs from previous multidimensional research (Webb, 2005, 2007; Chen \& Truscott, 2010), which notes that meaning knowledge was more difficult to acquire than form knowledge. The 
meaning of a word may be guessed from word parts knowledge and does not guarantee that other aspects of word knowledge are accomplished (Clarke \& Nation, 1980; Schmitt \& Meara, 1997). Wolter (2009) also argued that productive meaning was acquired incidentally from listening. It was also found that L2 learners may achieve knowledge of other word aspects without a mastery of word meaning (Schmitt, 1998; Van Zeeland \& Schmitt, 2013).

The current study shows that the word part knowledge seems to be achieved easily for Thai EFL participants. This is perhaps because it can be simply recognized and remembered from the grammatical rules of the word itself. Consistent with Webb (2005), the present results showed a propensity for the word form (spelling and word class) to advance before the word meaning. The form-meaning knowledge likely necessitates the translated definition of a word (L1 to L2 and L2 to L1), and understanding the definition of a word requires grammatical comprehension because the learners may guess the meaning of a word from its different parts or components. Nation (2013) also suggested that EFL learners may need the explanation and translation to attain the meaning of the words and may also require frequent encounters with the word. Therefore, the form and meaning of word knowledge appear to be superficially set at a similar stage and represent fundamental knowledge for the production of a word.

Finally, similar to previous studies, the word use (collocation knowledge) seemed to be the most difficult to acquire (Nation, 2013). Collocations were traditionally considered the most problematic for L2 learners (Peters, 2016), even if some studies indicated that collocations were easier than the derivative and multiple-meaning knowledge (González-Fernández \& Schmitt, 2019). Chui (2006) also found that receptive collocations knowledge was almost at a similar stage as productive knowledge of one derivation. However, this aspect necessitates a higher comprehension of knowledge than the retrieval of word knowledge. Indeed, EFL participants require high exposure to the language and the need for a high frequency of word usage.

Overall, despite some consistency between studies, the exact order of vocabulary development remains to be determined. This is partly because different methods may produce slightly different results (González-Fernández \& Schmitt, 2019). Indeed, different aspects may be studied, or other types of tests may be used, including different prompt words. Additionally, different learning techniques, treatments, and familiarity with the prompt words may affect test performance (Schmitt \& Meara, 1997). The learners' educational levels and personal characteristics will also impact their performance on various tests (González-Fernández \& Schmitt, 2019; Nontasee \& Sukying, 2020).

The current study supports earlier findings that some aspects of word knowledge are acquired before other aspects (Henriksen, 1999; Laufer \& Goldstein, 2004; Nation, 2013; Schmitt, 2000; Schmitt \& Zimmerman, 2002; Zimmerman, 2009; Sukying, 2017). The EFL participants showed a stronger recognition and recall of word parts and form-meaning link than collocation knowledge. It may imply that EFL learners are capable of form and meaning knowledge of a word than the ability to use a word. The students' performance revealed that the function of word knowledge was the most difficult level to achieve. This suggests that the acquisition of vocabulary knowledge among EFL participants follows a specific sequence. Learners first gain receptive word knowledge, which requires the ability to recognize the form and/or meaning of a word, then they acquire the ability to retrieve the production from lexical storage. In particular, the findings reveal the hierarchy of L2 word learnability in Thai high school participants. The aspects of form and meaning are likely fundamental knowledge for the production of a word. Indeed, the function of word knowledge involves perceiving lexical items' form and/or meaning (Nation, 2013). As such, the use of knowledge requires differing degrees of cognitive knowledge and metacognitive strategies (Hayashi \& Murphy, 2011). 
Regarding a continuum of word knowledge aspects (Research Question 2), the current findings reveal a positive relationship between different aspects of a word, both receptively and productively. This confirms that multiple aspects of a word are interrelated and suggest that knowing one aspect can advance other aspects' learning. The results imply that multiple aspects of word knowledge together are more useful in vocabulary acquisition than knowledge of a single aspect alone. That is, multiple closely related aspects of word knowledge positively influence the vocabulary acquisition of the learners. This is in line with the claim that the process of learning a word occurs on a developmental continuum (González-Fernández \& Schmitt, 2019; Lin, 2015a, 2015b; Nation, 2013; Schmitt \& Meara, 1997; Webb, 2008) and aligns with previous reports that receptive and productive word knowledge are positively correlated and facilitate vocabulary acquisition (Laufer \& Goldstein, 2004; Sukying, 2017, 2020). The current study indicates that the focus of vocabulary teaching and learning may be to strengthen receptive knowledge to facilitate progress in productive knowledge (Webb, 2005; Sukying, 2020).

To conclude, word learnability is an incremental learning process, where word form is easier to acquire and is achieved first, followed by meaning and, finally, use. Form and meaning are acquired at an initial stage, whereas the aspect of word use is needed a substantial lexical knowledge. Although this study indicates that word knowledge aspects follow a general difficulty order of L2 word learnability, this does not mean learning a word is always strictly completed in this sequence. The ease or difficulty in acquiring word knowledge depends on different factors, such as the idiosyncratic characteristics of the words, learning conditions and contexts, and learner proficiencies. Moreover, the number of encounters with the words will benefit learners in the development of their vocabulary.

\section{Conclusions}

The current study investigated the ease or difficulty of learning L2 word knowledge (word parts, form-meaning link, and collocations) in Thai high school learners and explored the relationship between multiple word knowledge aspects. The analysis of the current findings revealed that there were different difficulty levels of word knowledge to be acquired. Specifically, these findings indicated that acquiring a word is an incremental learning process. That is, the word parts are easier to acquire than the form-meaning link of the word, while collocations are the most difficult aspect to be learned. The current results also highlighted the close association between different word knowledge aspects, both receptively and productively. These findings confirmed the interrelated knowledge of word aspects as well as previous claims that learning a word occurs on a developmental continuum (Henriksen, 1999; Laufer \& Nation, 1995, 1999; Lin, 2015a, 2015b; Nation, 2013; Schmitt \& Meara, 1997; Sukying, 2017). In conclusion, each aspect of word knowledge contributes to word learnability; therefore, understanding the roles of word knowledge aspects can facilitate vocabulary acquisition and development.

\section{Recommendations}

This study explored the nature of word knowledge aspects and vocabulary development, particularly in Thai EFL learners. The results revealed a hierarchy of L2 word knowledge in vocabulary teaching and learning in English language instruction, which could be used to develop the comprehension and production of a word in EFL learners. Nevertheless, longitudinal research is required to investigate vocabulary acquisition patterns and better understand the nature of different word knowledge aspects and their impact on L2 word learnability. Furthermore, it would be worthwhile to explore the longitudinal changes at different educational levels, such as primary school, junior high school, and university. In the current study, the administration of the word knowledge tests 
was time-consuming. Therefore, using a time-saving mode of testing, such as an adaptive computer test, may benefit future research. Other instruments, such as observation, questionnaires, and interviews, based on qualitative methodology, should also be used to ensure the reliability and validity of the data and gain additional information regarding vocabulary acquisition. Importantly, future studies should ensure that the content of the tests and the tests themselves are adapted to the context. Finally, there is a pressing need to measure all 18 aspects of word knowledge to explore the developmental process of vocabulary learning and varying perspectives of word knowledge.

\section{Ethics Committee Approval}

The authors confirm that the study does not need ethics committee approval according to the research integrity rules in their country (Date of Confirmation: December 18, 2019).

\section{References}

Akbulut, D. F. (2017). Effects of Morphological Awareness on Second Language Vocabulary Knowledge. Journal of Language and Linguistic Studies, 13(1), 10-26.

Anderson, R. C., \& Freebody, P. (1981). Vocabulary knowledge. In J. Guthrie (Ed.), Comprehension and Teaching: Research Reviews (pp. 77-117). International Reading Association.

Anderson, R. C., \& Freebody, P. (1983). Reading comprehension and the assessment and acquisition of word knowledge. In B. Hutton (Ed.), Advances in reading/language research: A research annual (pp. 231-256). JAI Press.

Barcroft, J. (2002). Semantic and structural elaboration in L2 lexical acquisition. Language Learning, 52(2), 323-263.

Bauer, L., \& Nation, I. S. P. (1993). Word families. International Journal of Lexicography, 6(4), 253279.

Begagić, M. (2016). English language students' productive and receptive knowledge of collocation. Explorations in English Language and Linguistics, 2(1), 46-67.

Brown, D. (2011). What aspects of vocabulary knowledge do textbooks give attention to? Language Teaching Research, 15, 83-97.

Browne, C., Phillips, J., \& Culligan, B. (2013). New General Service List. Retrieved March 10, 2020, from http://www.newgeneralservicelist.org/

Chawwang, N. (2008). An investigation of English reading problems of Thai 12th Grade Students in Nakhonratchasima Educational Regions 1,2,3 and 7. [Master's thesis, Srinakharinwirot University].

Chen, C., \& Truscott, J. (2010). The effects of repetition and L1 lexicalization on incidental vocabulary acquisition. Applied Linguistics, 31(5), 693-713.

Chui, A. (2006). A study of the English vocabulary knowledge of university students in Hong Kong. Asian Journal of English Language Teaching, 16, 1-23.

Clarke, D. F., \& Nation, I. S. P. (1980). Guessing the meanings of words from context: Strategy and techniques. System, 8(3), 211-220.

Cohen, J. (1988). Statistical power analysis for the behavioral sciences (2nd ed.). Lawrence Erlbaum.

Cohen, J. (1992). A power primer. Psychological Bulletin, 112(1), 155-159. 
Corson, D. J. (1995). Using English Words. Kluwer Academic Publishers.

Coxhead, A. (2000). A new academic word list. TESOL Quarterly, 34(2), 213-238.

Daskalovska, N. (2016). Acquisition of three word knowledge aspects through reading. The Journal of Educational Research, 109(1), 68-80.

DeVellis, R. F. (2003). Scale Development: Theory and Applications (2nd ed.). Sage.

Dörnyei, Z. (2007). Research methods in applied linguistics. Oxford University Press.

Ellis, N. C. (2013). Second language acquisition. In G. Trousdale \& T. Hoffmann (Eds.), Oxford handbook of construction grammar (pp. 365-378). Oxford University Press.

Ellis, N. C., \& Beaton, A. (1993). Psycholinguistic determinants of foreign language vocabulary learning. Language Learning, 43, 559-617.

Fitzpatrick, T., \& Izura, C. (2011). Word association in L1 and L2. Studies in Second Language Acquisition, 33(3), 373-398.

González-Fernández, B., \& Schmitt, N. (2019). Word knowledge: Exploring the relationships and order of acquisition of vocabulary knowledge components. Applied Linguistics, 41(4), 481-505. https://doi.org/10.1093/applin/amy057

Hayashi, Y., \& Murphy, V. (2011). An investigation of morphological awareness in Japanese learners of English. Language Learning Journal, 39(1), 105-120.

Henriksen, B. (1999). Three dimensions of vocabulary development. Studies in Second Language Acquisition, 21(2), 303-317.

Jamtawee, T. (2000). Reading a Foreign language: Similarities and Differences between English and German. Thammasart Review, 5(1), 134-146.

Kieffer, M. J., \& Lesaux, N. K. (2012). Knowledge of words, knowledge about words: Dimensions of vocabulary in first and second language learners in sixth grade. Reading and Writing, 25(2), 347373.

Kittigosin, R., \& Phoocharoensil, S. (2015). Investigation into learning strategies and delexical verb use by Thai EFL learners. 3L: The Southeast Asian Journal of English Language Studies, 21(2), 63-72.

Kotchana, S., \& Tongpoon-Patanasorn, A. (2015). EFL learners' vocabulary size: A case in the northeastern region of Thailand. ASEAN Journal of Education, 1(1), 9-26.

Larson-Hall, J. (2016). A guide to doing statistics in second language research using SPSS (2nd ed.). Routledge.

Larson-Hall, J., \& Herrington, R. (2010). Improving data analysis in second language acquisition by utilizing modern developments in applied statistics. Applied Linguistics, 31(1), 368-390.

Laufer, B. (1989). A factor of difficulty in vocabulary learning: deceptive transparency. AILA Review, 6, 10-20.

Laufer, B. (1992). Reading in a foreign language: how does L2 lexical knowledge interact with the reader's general academic ability? Journal of Research in Reading, 15(2), 95-103.

Laufer, B. (1998). The development of passive and active vocabulary: Same or different? Applied Linguistics, 19(2), 255-271. 
Laufer, B. (2013). Second language word difficulty. In C. A. Chapelle (Ed.), The encyclopedia applied linguistics (pp. 5151-5156). Wiley-Blackwell.

Laufer, B., \& Goldstein, Z. (2004). Testing vocabulary knowledge: Size, strength, and computer adaptiveness. Language Learning, 54(3), 399-436.

Laufer, B., \& Nation, I. S. P. (1995). Vocabulary size and use: Lexical richness in L2 written production. Applied Linguistics, 16(3), 307-322.

Laufer, B., \& Nation, I. S. P. (1999). A vocabulary-size test of controlled productive ability. Language Testing, 16(1), 33-51.

Laufer, B., \& Paribakht, T. S. (1998). The relationship between passive and active vocabularies: effects of language learning context. Language Learning, 48(3), 365- 391.

Li, M., \& Kirby, J. R. (2015). The effects of vocabulary breadth and depth on English reading. Applied Linguistics, 36(5), 611-634.

Liangpanit, C. (2014). Vocabulary Teaching and Learning in Thai EFL Contexts: Findings and Implication. Songklanakarin Journal of Social Sciences and Humanities, 15(3), 119-131.

Lin, C. C. (2015a). L2 word processing: A review from a word form perspective. University of Sydney Papers in TESOL, 10, 129-154.

Lin, C. C. (2015b). L2 word learnability: A focus on written form of words. [Doctoral dissertation, University of Sydney].

Mackey, A., \& Gass, S. M. (2005). Second language research: Methodology and design. Erlbaum.

Meara, P. (1983). Word associations in a foreign language: A report on the Birkbeck vocabulary project. Notts Ling.

Meara, P. (1984). The study of lexis in interlanguage. In A. Davies, C. Criper, \& A. Howatt (Eds.), Interlanguage (pp. 225-235). Edinburgh University Press.

Meara, P. (1997). Towards a new approach to modelling vocabulary acquisition. In N. Schmitt \& M. McCarthy (Eds.), Vocabulary: Description, acquisition, and pedagogy. Cambridge University Press.

Meara, P., \& Buxton, B. (1987). An alternative to multiple choice vocabulary tests. Language Testing, $4(2), 142-154$.

Melka, F. (1997). Receptive vs. productive aspects of vocabulary. In N. Schmitt \& M. McCarthy (Eds.), Vocabulary: Description, Acquisition, and Pedagogy (pp. 84-102). Cambridge University Press.

Milton, J., \& Fitzpatrick, T. (2014). Dimensions of vocabulary knowledge. Palgrave Macmillan.

Milton, J., \& Hopkins, N. (2006). Comparing phonological and orthographic vocabulary size: Do vocabulary tests underestimate the knowledge of some learners? Canadian Modern Language Review, 63(1), 127-147.

Ministry of Education of Thailand. (2008). The Basic Education Core Curriculum. 2551, 281.

Morgan, C. L., \& Bonham, D. N. (1944). Difficulty of vocabulary learning as affected by parts of speech. Journal of Educational Psychology, 35(6), 369-377. 
Nagy, W. E., Diakidoy, I. N., \& Anderson, R. C. (1993). The acquisition of morphology: Learning the contribution of suffixes to the meanings of derivatives. Journal of Reading Behavior, 25(2), 155170 .

Nation, I. S. P. (1983). Testing and teaching vocabulary. Guidelines, 4(1), 12-25.

Nation, I. S. P. (1990). Teaching and learning vocabulary. Heinle and Heinle.

Nation, I. S. P. (2001). Learning vocabulary in another language. Cambridge University Press.

Nation, I. S. P. (2013). Learning vocabulary in another language (2nd ed.). Cambridge University Press.

Nation, I. S. P., \& Beglar, D. (2007). A vocabulary size test. The Language Teacher, 31(7), 9-13.

Nontasee, W., \& Sukying, A. (2020). The acquisition of vocabulary knowledge in Thai EFL high school students. Journal of Man and Society Faculty of Humanities and Social Sciences, 6(1), 6387.

Palmberg, R. (1987). Patterns of vocabulary development in foreign-language learners. Studies in Second Language Acquisition, 9(2), 201-220.

Pellicer-Sánchez, A., \& Schmitt, N. (2010). Incidental vocabulary acquisition from an authentic novel: Do things fall apart? Reading in a Foreign Language, 22(1), 31-55.

Peters, E. (2016). The learning burden of collocations: The roles of interlexical and intralexical factors. Language Teaching Research, 20, 113-138.

Phoocharoensil, S. (2013). Cross-linguistic influence: Its impact on L2 English collocation production. English Language Teaching, 6(1), 1-10.

Phoocharoensil, S. (2014). Exploring learners' developing L2 collocational competence. Theory and Practice in Language Studies, 4(12), 2533-2540.

Pigada, M., \& Schmitt, N. (2006). Vocabulary acquisition from extensive reading: A case study. Reading in a Foreign Language, 18(1), 1-28.

Read, J. (2000). Assessing Vocabulary. Cambridge University Press.

Richards, J. C. (1976). The role of vocabulary testing. TESOL Quarterly, 10(1), 77-89.

Schmitt, N. (1998). Tracking the incremental acquisition of second language vocabulary: A longitudinal study. Language Learning, 48(2), 281-317.

Schmitt, N. (2000). Vocabulary in language teaching. Cambridge University Press.

Schmitt, N. (2008). Instructed second language learning. Language Teaching Research, 12(3), 329363.

Schmitt, N. (2008). Review article: Instructed second language vocabulary learning. Language Teaching Research, 12(3), 329-363.

Schmitt, N. (2010). Researching vocabulary: A vocabulary research manual. Palgrave Macmillan.

Schmitt, N. (2014). Size and depth of vocabulary knowledge: What the research shows. Language Learning, 64(4), 913-951.

Schmitt, N., \& Meara, P. (1997). Researching vocabulary through a word knowledge framework: Word associations and verbal suffixes. Studies in Second Language Acquisition,19(1), 17-36. 
Schmitt, N., \& Zimmerman, C. B. (2002). Derivative word forms: What do learners know? TESOL Quarterly, 36(2), 145-171.

Schmitt, N., Schmitt, D., \& Clapham, C. (2001). Developing and exploring the behavior of two new versions of the Vocabulary Levels Test. Language Testing, 18(1), 55-88.

Schneider, V. L., Healy, A. F., \& Bourne, L. E. Jr. (2002). What is learned under difficult conditions is hard to forget: Contextual interference effects in foreign vocabulary acquisition, retention, and transfer. Journal of Memory and Language, 46(2), 419-440.

Staehr, L. S. (2009). Vocabulary knowledge and advanced listening comprehension in English as a foreign language. Studies in Second Language Acquisition, 31(4), 577-607.

Sukying, A. (2017). The relationship between receptive and productive affix knowledge and vocabulary size in an EFL Context. [Doctoral dissertation, University of Sydney].

Sukying, A. (2018a). The acquisition of English affix knowledge in L2 learners. NIDA Journal of Language and Communication, 23(34), 89-102.

Sukying, A. (2018b). Investigating receptive and productive affix knowledge in EFL learners. In D. Hirsh (Ed.), Explorations in second language vocabulary research (pp. 183-218). Peter Lang.

Sukying, A. (2020). Word knowledge through morphological awareness in EFL learners. TESOL International Journal, 15(1), 74-85.

Supa-Siraprapa, S. (2019). The effect of learning environments on Thai speakers' English L2 vocabulary depth. PASAA, 57, 101-132.

Van Zeeland, H., \& Schmitt, N. (2013). Incidental vocabulary acquisition through L2 listening: A dimensions approach. System, 41, 609-624.

Verspoor, M., \& Lowie, W. (2003). Making sense of polysemous words. Language Learning, 53(3), 547-586.

Vincy, I. R. (2020). Examining the effect of explicit instruction on vocabulary learning and on receptive-productive gap: An experimental study. Journal of Language and Linguistic Studies, 16(4), 2040-2058. Doi: 10.17263/jlls.851033

Webb, S. (2005). Receptive and productive vocabulary learning: The effect of reading and writing on word knowledge. Studies in Second Language Acquisition, 27(1), 33-52.

Webb, S. (2007). The effects of synonymy on second-language vocabulary learning. Reading in a Foreign Language, 19(2), 120-136.

Webb, S. (2008). Receptive and productive vocabulary sizes of L2 learners. Studies in Second Language Acquisition, 30(1), 79-95.

Webb, S. (2009). The effects of receptive and productive learning of word pairs on vocabulary knowledge. RELC Journal, 40(3), 360-376.

Wesche, m., \& Paribakht, T. S. (1996). Assessing second language vocabulary knowledge: Depth versus breadth. The Canadian Modern Language Review, 53(1), 13-40.

Wolter, B. (2009). Meaning-last vocabulary acquisition and collocational productivity. In T. A. Fitzpatrick (Ed.), Lexical Processing in Second Language Learners: Papers and Perspectives in Honour of Paul Meara. Multilingual Matters. 


\section{Appendix}

\section{Appendix A. An example of the Word Segmentation Test (WST)}

Instructions: Break down a word into the smallest parts.

availability

$=$

\section{Appendix B. An example of the Affix Elicitation Task (AET)}

Instructions: Choose an appropriate part of speech in part B to complete the sentence in part A.

\begin{tabular}{|c|c|c|c|c|}
\hline \multirow[t]{2}{*}{ A. Fill in the blank } & \multicolumn{4}{|c|}{$\begin{array}{l}\text { B. Missing part of } \\
\text { speech }\end{array}$} \\
\hline & $\mathrm{N}$ & $\mathrm{V}$ & Adj. & Adv \\
\hline I am not __ tonight because I need to study for an English exam. (avail) & & & & \\
\hline
\end{tabular}

\section{Appendix C. An example of the L1 Translation Test (L1TT)}

Instructions: Choose the word with a similar meaning.

Book
a) reserve
b) revenge
c) remove
d) restore

\section{Appendix D. An example of the L2 Translation Test (L2TT)}

Instructions: Read the meaning of the following words in Thai and complete the English words with the first letter given.
$=\mathbf{A}$

\section{Appendix E. An example of the Collocation Recognition Test (CRT)}

Instructions: Choose the best word choice in the first column to describe the noun in the second.

\begin{tabular}{lll}
\hline Adjective & \multicolumn{2}{c}{ Noun } \\
\hline thirsty & 1. & expert \\
professional & 2. & approach \\
smelled & & \\
conventional & & \\
\hline
\end{tabular}




\section{Appendix F. An example of the Productive Collocation Recall Test (PCRT)}

Instructions: Complete the sentence below with an appropriate word. The first two letters are provided.

Taking the IELTS is my first re challenge of my student's life.

\section{AUTHORS BIODATA}

Worakrit Nontasee is a PhD student in English Language Teaching (ELT) Programme, Mahasarakham University, Maha Sarakham, Thailand. His research interests are L2 vocabulary acquisition and second language acquisition (SLA).

Apisak Sukying is an assistant professor in English language teaching at Mahasarakham University, Thailand. He completed his Ph.D. in TESOL from the University of Sydney, Australia. His research interests include L2 vocabulary acquisition, academic writing, SLA, ESP, and ELT. 